\title{
Reply to Technical Details and Results of a Minimally Invasive Management of Gastric Band Erosions: a Series of 47 Patients
}

\author{
Guillaume Lafaurie $^{1} \cdot$ Rehana Hafeez $^{1} \cdot$ Shamsi El-hassani $^{1}$
}

Published online: 23 April 2020

(C) Springer Science+Business Media, LLC, part of Springer Nature 2020

\section{Dear Authors,}

We read with great interest your article entitled Technical Details and Results of a Minimally Invasive Management of Gastric Band Erosions: a Series of 47 Patients [1]. First and foremost, we would like to congratulate the authors for their successful approach. We principally agree with the contents of your article, and in order to complement the scientific value of your article, we would like to share our experience in the management of this difficult gastric band complication (0.5$3.8 \%$ ) [2]. Initially, we used to wait for near total erosion [3-7] and this will make surgical removal easier and safer; however, we changed our practice based on the following two points:

1- Some of these patients with gastric band erosions present with a rare complication of left phrenic abscess (11.6\%) [8] which made the surgical management much more complicated, challenging in the presence of local sepsis. Needless to say, systemic manifestation of this type of sepsis is serious. Although the process of band erosions is benign, slow and generally asymptomatic (the erosions being compensated by the healing of the gastric wall), it's at risk to develop this rare complication due to small leak making the surgical management more complicated and critical. We realised by early removal once erosions are detected, we may prevent this septic complication.

2- Waiting for near-total erosion basically allows total vagotomy with all the possible complications (abdominal pain, dumping syndrome and diarrhoea). On a similar note, it was interesting that some of our patients developed these symptoms post band erosions on the wait and watch policy (change in bowel habits in the form of loose stool and diarrhoea).

Guillaume Lafaurie

Guillaume.lafaurie89@gmail.com

1 Department of General Surgery, Princess Royal University Hospital, Farnborough Common, Orpington BR6 8ND, UK
Therefore, it's now the policy in our department to remove the band at the earliest convenience once a gastric band erosion has been diagnosed even if the surgical approach can be challenging.

\section{Compliance with Ethical Standards}

Conflict of Interest The authors declare that they have no conflict of interest. This article does not contain any studies with human participants or animals performed by any of the authors.

Informed Consent Informed consent does not apply.

\section{References}

1. Furbetta N, Gragnani F, Cervelli R, et al. Technical details and result of a minimally invasive management of gastric band erosions: a series of 47 patients. Obes Surg. 2019;29:3754-61. https://doi.org/ 10.1007/s11695-019-04170-2.

2. Lattuada E, Zappa MA, Mozzi E, et al. Band erosion following gastric banding: how to treat it. Obes Surg. 2007;17(3):329-33. https://doi.org/10.1007/s11695-007-9060-z.

3. Chisholm J, Kitan N, Toouli J, et al. Gastric band erosion in 63 cases: endoscopic removal and rebanding evaluated. Obes Surg. 2011;21(11):1676-81. https://doi.org/10.1007/s11695-011-0468-0.

4. Regusci L, Groebli Y, Meyer JL, et al. Gastroscopic removal of an adjustable gastric band after partial intragastric migration. Obes Surg. 2003;13(2):281-4. https://doi.org/10.1381/096089203764467216.

5. Kurian M, Sultan S, Garg K, et al. Evaluating gastric erosion in band management: an algorithm for stratification of risk. Surg Obes Relat Dis. 2010;6(4):386-9. https://doi.org/10.1016/j.soard.2009.11.020.

6. Egberts K, Brown WA, O'Brien PE. Systematic review of erosion after laparoscopic adjustable gastric banding. Obes Surg. 2011;21(8): 1272-9. https://doi.org/10.1007/s11695-011-0430-1.

7. Abu-Abeid S, Zohar DB, Sagie B, et al. Treatment of intra-gastric band migration following laparoscopic banding: safety and feasibility of simultaneous laparoscopic band removal and replacement. Obes Surg. 2005;15(6):849-52. https://doi.org/10.1381/ 0960892054222696 .

8. Nguyen NT, De Maria EJ, Ikramuddin S, et al. The SAGES manual: a practical guide to bariatric surgery. In The SAGES Manual: a practical guide to bariatric surgery. 2008. https://doi.org/10.1007/978-0387-69171-8.

Publisher's Note Springer Nature remains neutral with regard to jurisdictional claims in published maps and institutional affiliations. 